\title{
The Prospects for an International Language
}

\author{
Andrew Large* \\ Mcgrill University, Montreal
}

\begin{abstract}
Reviews the various arguments that have been advanced since the seventeenth century in favor of adopting one common language for international communication. Discusses the barriers that have prevented any constructed language from assuming this role. Considers the possibility of a natural language acting as a medium for international communication and in Particular evaluates the extent to which English now occupies this position.
\end{abstract}

\section{Motives for Language Construction}

Close to one thousand artificial languages have been constructed to date, with almost all of them appearing since the early seventeenth century (Dulicenko, 1989). What, other than the challenge and joy of creating a language, has motivated so many people to invest their energies in this endeavor?

Some language planners, and especially the seventeenth-century thinkers such as Rene Descartes, George Dalgarno and John Wilkins, were concerned to devise a universal language in accordance with scientific principles (Large, 1985). Such a language would be better suited to the communication of

\footnotetext{
Director and Professor, Graduate School of Liberary \& Information Studies McGrill University, Montreal, Canada, 3459 Mctavish, Quebec H3A IYI
} 
philosophical truth than the imperfect natural languages, including Latin which then served as a medium of international communication between the learned of Europe. The objective was to relationship between things in the real world by the language itself. The language would be free of ambiguities and irregularities, instead it would enable ideas to be expressed concisely and clearly with no for misunderstanding. Descartes, for example, proposed the language from simple elements identified by rational. These elements could then be combined according to rules in order to express complex ideas, much as a library classification scheme might enable representations of complex subjects to be assembled by combining the representations of several simple subjects.

Although several languages were constructed in the seventeenth century according to such philosophical principles, they failed to win widespread support and by the turn of the century interest in them had largely evaporated. In part this was because they were simply too complicated in structure to attract many learners. More fundamentally, their scientific nature itself was flawed: the classification of knowledge on which languages like Wilkins' Real Character (1668) was based proved quickly to be inadequate. Constant revision would have been necessary to take account of scientific discoveries. Furthermore, the classificatory approach to scientific study, based upon Aristotelian philosophy, was being replaced by a new atomistic philosophy that rejected the notion of the universe as a classification schedule.

A second dominant motive shared by many language planners has been the desire to eradicate human conflict and introduce an era of universal peace and happiness. A common language shared by all peoples, it is argued, would eliminate many of the causes of friction between peoples. This motive was especially apparent in the schemes created in the late nineteenth century. As the creator of Esperanto, Zamenhof, expressed it when describing his childhood experiences in Poland: "In this town, more than anywhere else, an impressionable nature feels the heavy burden of linguistic differences and is convinced, at every step, that the diversity of 
languages is the only, or at least the main cause, that separates the human family and divides it into conflict groups" (Boulton, 1960, P.7) To take one more example, Schleyer envisaged his language, Volapuk, as contributing to human unity and universal peace (Large, 1985). In the twentieth century, also, many people associated linguistic diversity with national conflict. As Albert Guerard(1945) wrote in the final year of the Second World War. "The main cause of war... is jealous nationalism. And nationalism has a tendency to translate itself into linguistic terms." More recently, Glossop(1988) argued that peace, economic well-being and social justice in the world can best be realised if everyone learns a common second neutral language such as Esperanto. The causes of war are complex and defy analysis here. It is clear, however, that warfare can take place between groups sharing a common language; the American Civil War cost as many American lives as all its other wars before or since combined, and the present conflict in former Yugoslavia between Serbs, Bosnians and Croats is just one more proof that a shared language is no recipe for a peaceful existence.

The third main motivation for construction a language is to facilitate international communication by providing a common medium which can be employed by everyone regardless of native language. The desire to improve communication between peoples using diverse tongues has been a motivating force behind most if not all language schemes. As international contacts deepen at many levels - political, economic and cultural - the arguments in favor of an international auxiliary language become ever stronger. It is estimated that there are some five thousand languages spoken on earth, although four thousand or so are have less than ten thousand speakers each and only about two hundred are spoken by more than one million people (de Swaan, 1991). In contacts at an international level, then, the chances of two individuals from different parts of the globe having the same native language are not high. In many cases it is necessary to resort to translators and interpreters, or perhaps to muddle through using a language in which one or more of the communicators lacks proficiency. How much better, it is 
argued, to have one language internationally accepted for such communication between people from different language groups.

\section{Arguments in Favor of Constructed languages}

If a common language is needed for international communication, why not choose one of the five thousand existing natural languages rather than going to the time and trouble of creating yet another language? Answers from language planners tend to emphasise two virtues to be found in constructed languages but not in natural languages: simplicity and neutrality.

Simplicity in a language is seen as a virtue because "simple" languages prima facie should be easier to learn and apply as a second language than "complex" languages. If the world's population is to acquire a language for international communication that is different from the one(s) used within their country or region, then it is preferable that this can be done with as little lime and effort as possible. What makes a language simple to learn and use? It is probably safe to assume that a language with few or no irregularities in grammar, morphology and phonology will be easier to learn than one with many exceptions to every rule. Natural languages normally do not exhibit a great deal of regularity: they abound with exceptions to rules that no language planner would dream of incorporating in a constructed language. Some constructed languages, such as the seventeenth-century philosophical languages mentioned above, or the early nineteenth-century Solresol (based upon the seven notes of the Sol-fa musical scale) were not designed primarily for simplicity of learning or use and were complicated to master (Large, 1985). In many cases, however, language planners have deliberately sought simplicity. This is especially true of the more naturalistic languages constructed in the late nineteenth and twentieth centuries. The list is long of languages whose creators considered them easy to learn. Interestingly, much of the acrimonious debate between the supporters of rival constructed 
languages has centered upon their presumed ease of use. Schleyer considered his Volapuk was easy to learn, but many critics considered its grammar complicated (although regular), pronunciation difficult and word formation convoluted (Large, 1985). Esperanto prides itself on simplicity: spelling and pronunciation are broadly phonetic; the grammar is regular (and was encapsulated by Zamenhof in just sixteen rules); and word formation is regular. Nevertheless, the language has been subject to prolonged criticism, including its use of accented letters, arbitrary word formation, and use of the accusative case. As Dulicenko (1989) comments, constructed languages begin with an unvarying structure, attempting to achieve one element for one meaning. But if the language then attracts speakers, they tend to furnish the characteristics found in natural languages - ambiguity, synonymy and homonymy. Piron (1989) gives examples of linguistic evolution in Esperanto that demonstrate it is a living language but which move it away from the initial plan formulated by its creator.

If regularity of linguistic structure is one way to achieve simplicity in a constructed language, a second way is to seek naturalness. By this is meant the incorporation of grammatical, morphological or phonological features which will be familiar to the learners and users of the language. The ease of learning a language is likely to be related closely to a person's native language and to other "foreign" languages that person may have learned. A native English-speaker may well find French easier than would a Korean; a Korean who has already learned English, however, may then find French less difficult to pick up than a monolingual compatriot. So long as language planners had a limited view of their potential market, an artificial language could be developed which would seem familiar, say, to speakers of Romance languages because the language would incorporate grammar and vocabulary primarily from French, Italian, Spanish, etc. an example is occidental, constructed in the early twentieth century at a time when its author could believe that the majority of the people who have international relationships were confined to Western Europe (Large, 
1985). Unfortunately, the element of naturalness can only be purchased at the price of irregularities. Such irregularities would hardly appeal to those learners of Occidental whose mother tongue did not belong to the Romance family.

This leads into the second presumed advantage for a constructed language over a natural language as a medium for international communication: its neutrality. A natural language, by definition, is the mother tongue of some people, though that number will vary greatly according to the individual language. If any natural language is adopted as the international language, its speakers will enjoy several major advantages. Firstly, they will not have to spend time in learning the international language. Secondly, as native speakers they will have a fluency and command of the language that may be hard to equal for those who have learned it as a second language. Thirdly, as language is intimately linked with culture (in its broadest sense) the adoption of a language for international usage is likely to promote the culture of the native speakers of that language. Constructed languages, in contrast, are native to none and therefore do not bestow advantages on some people at the expense of others.

There is validity to this argument Natural languages do "belong" to some people and not others, while constructed languages are the property of all who learn them as a second language. This should not conceal, however, the problems in constructing a language that is to be truly universal in the sense of being equally easy (or difficult) to learn regardless of native language. Given their historical origin in Europe, many constructed languages exhibit features from Romance, Germanic and Slavic languages that are more familiar to (and therefore more easily learned by) Europeans than, say, peoples in East Asia. In the late nineteenth century this would not have seemed a problem to the Eurocentric supporters of such languages. As the need for a genuinely international (rather than pan-European) language has become self- evident, proponents of the various constructed languages now debate the universality of their schemes. Esperanto closely resembles a number of languages in the IndoEuropean family both in grammar and vocabulary, simply because it 
was largely based on the Romance languages or drawn directly from Latin, with smaller roles for German, Russian, English and Polish. Esperantists assert that their language is becoming less IndoEuropean just because so many of its users are non-Europeans and they are playing a part in developing its vocabulary (see, for example, Sonnenfeld, 1988). A cursory glance at an Esperanto text, however, reveals its linguistic origins: a French speaker can guess at the meaning of an Esperanto text with surprising success; can the same really be said of a Korean?

Even if it be conceded that constructed languages do have advantages over natural languages in terms of simplicity and neutrality, they exhibit one drawback compared with natural languages that to date has negated any positive features: constructed languages do not have a foundation of native speakers, generation after generation, to build upon nor the power of a national state to advance their interests. It is true, of course, that a small number of children grow up using a constructed language - normally Esperanto - either as mother tongue or as one of several languages (bilingually or mulrilingually). But these are the exceptions. A neutral constructed language which will serve as the medium for international communication by definition will be a second language which has to be learned by all its users. How are potential users to be persuaded to invest their time, effort and money in learning even the simplest of constructed languages unless they are sure that enough other people around the world with whom they communicate will have done likewise? No constructed language movement has found an answer. The most successful of all these languages is Esperanto. No other constructed language comes close by any measure - number of speakers (however defined and counted), world distribution of speakers, longevity of the movement, organizational strength, number of publications, variety of publications (original and translation), etc. After more than one hundred years the number of Esperanto speakers remains very small. Estimates world-wide range enormously from 100,000 to sixteen million (Maxwell, 1988). The latter, almost certainly, greatly 
exaggerates the number of fluent speakers, and the lower figure seems more realistic. (Large, 1985). The World Almanac estimates two million speakers, but even this number is only equivalent to the number of Estonian or Icelandic speakers, and less than one thirtieth of Korean speakers. In any case, it is small by comparison with around twelve natural languages each of which has at least one hundred million speakers. It seems highly improbable that any constructed language in the foreseeable future will achieve through natural diffusion the critical mass to attract adherents in sufficient numbers to make it truly a language for international communication.

An alternative would be for an international forum like the United Nations, with support from a majority of countries, to adopt a constructed language to serve as an international language. Pei(1958) suggested that an international commission of linguists could be established to select the language. In this case countries might then provide the resources and incentives for their nationals to learn that language, ideally within the school curriculum. If this could be achieved then a critical mass of speakers could be expected to develop. Such a scenario would require a measure of international cooperation seldom encountered in the political arena. There is no indication of its imminent realisation, however rational it may seem. It would also require a decision to be taken on which constructed language would serve this purpose. It is by no means clear that Esperanto would be selected, despite its many attributes. The history of the international language movement, if it demonstrates nothing else, reveals that agreement upon the virtues of any particular constructed language is difficult to gain. It is hard to see an international panel of "experts" readily agreeing on any language. The problem with a constructed language is that it can be constructed in many different ways, giving endless scope for debate and controversy. 


\section{Natural Languages}

Among the dozen languages in the world with the most speakers, only a few are used almost exclusively by native speakers communicating among themselves and within a relatively compact linguistic area: Bengali, Japanese and German are good examples. Most of the largest languages serve not only as mother tongue but also as a lingua franca between peoples with different native languages (de Swaan, 1991). A few languages can be considered global in the sense that they are widely used across several continents: French, Spanish and above all English. The explanation for this diffusion can be found, of course, in the colonising activities of France, Spain, Britain and, more recently, the United States. Language followed in the wake of soldiers, missionaries and merchants. In any discussion of an international language for global communication, it is necessary to assess the extent to which one natural language in particular - English - de facto has already assumed that universal role.

\section{English as International language}

The number of English speakers world-wide is difficult to estimate with any accuracy. Around 350 million people use English as a first language in about 75 territories (Crystal, 1995). Many more can read, write or speak English as a foreign language. In number of native speakers, then, English is second only to Chinese. When measured by the number of non-native speakers who can communicate through this language, however, English is far ahead of Chinese. It would be difficult to dispute the widespread use of English as an international language for science and technology, business, data transfer, tourism and youth culture in general. In a growing number of countries, English is the major foreign language studied in the school curriculum. De Swaan (1991) calls English the "supercentral language" 
It is relatively easy to measure the usage of languages in science and technology, at least as expressed in numbers of scientific publications. Databases containing references to the world's literature in various scientific and technical fields can be analysed quickly to establish the language of communication. Table 1 shows the distribution of scientific publications in four fields for just one year: 1990. The dominance of a small number of languages in all these fields is clearly demonstrated, and in particular the leading role (quantitatively at least) of English. In all four scientific areas, just five languages (English, German, French, Russian and Japanese) account for more than ninety percent of all publications. Even making allowance for some exaggeration in the percentage of English-language publications listed in these American databases, the pre-eminent role of English is undeniable (these databases are successful in identifying large numbers of documents: 1990 publications losted were as follows: Biosciences, 555, 773; Medicine, 375, 416: chemistry, 513, 872; and food sciences, 9326). Widely-spoken languages such as Spanish and Chinese are relatively unimportant vehicles for the transfer of scientific information.

Table 1. Distribution of publication languages in four scientific fields

$\begin{array}{lllll}\text { Language } & \text { Biosciences } & \text { Medicine } & \text { Chemistry } & \text { Food Sciences } \\ \text { English } & 87.2 \% & 79.5 \% & 66.8 \% & 71.2 \% \\ \text { German } & 2.1 \% & 3.9 \% & 3.8 \% & 8.7 \% \\ \text { French } & 1.6 \% & 2.9 \% & 0.9 \% & 4.3 \% \\ \text { Spanish } & 0.8 \% & 1.5 \% & 0.3 \% & 0.6 \% \\ \text { Russian } & 3.6 \% & 4.4 \% & 10.1 \% & 3.6 \% \\ \text { Japanese } & 1.9 \% & 2.6 \% & 13.2 \% & 2.7 \% \\ \text { Chinese } & 0.7 \% & 0.8 \% & 2.7 \% & 0.5 \% \\ \text { Korean } & 0.2 \% & 0.03 \% & 0.3 \% & 0.4 \%\end{array}$

It is also interesting to look at the changes in language distribution over a twenty-year time period. Table 2 shows the 
relative distribution of languages in just one field: chemistry over twenty years. It reveals a growing dominance (proportionately) for English as Japanese, Chinese and Korean, with a decline in French, German and Russian. The biggest growth is found in Chinese publications; nevertheless, Chinese has a long way to go to overtake English.

Table 2. Changes in language distribution of chemistry publications, 1970-1990

$\begin{array}{llll}\text { Language } & 1970 & 1980 & 1990 \\ \text { English } & 47.1 \% & 59.8 \% & 66.8 \% \\ \text { German } & 5.4 \% & 5.7 \% & 3.8 \% \\ \text { French } & 3.7 \% & 2.1 \% & 0.9 \% \\ \text { Spanish } & 0.5 \% & 0.5 \% & 0.3 \% \\ \text { Russian } & 19.7 \% & 15.7 \% & 10.1 \% \\ \text { Japanese } & 2.9 \% & 11.1 \% & 13.2 \% \\ \text { Chinese } & 0.02 \% & 0.8 \% & 2.7 \% \\ \text { Korean } & 0.1 \% & 0.2 \% & 0.3 \%\end{array}$

Garfield and Welljams-Dorof(1990) demonstrate from the Institute for Scientific Information's Scisearch database that almost half of the publications appearing in 1984 in English (accounting for almost $\mathrm{d} 5 \%$ of the publications) were written by authors outside the US, UK, Canada and Australia, many of whom will be using English as a second language. Their motive is simple: the widest audience for their research can be found by publishing in English. A search on the same database from 1974 to 1995 retrieved 176 documents written by authors from Korean institutions. 169 of which were in English rather than Korean.

To take another example, Internet is estimated to have between 20 million and 40 million users worldwide. If these net surfers are to communicate via this network of electronic networks they must do so by using a language and the overwhelmingly dominant language currently is English (Cumming, 1995). Malaysia, which has been 
emphasising its Malay language, is starting to offer more education in English to prepare its citizens for the information age. Those who do not know English face problems. As an official of I-Net Technologies, an Internet access provider in South Korea, is quoted as saying, "It's not only English you have to understand, but American culture, even slang. All in all, there are many people who just give up." In Japan, even the Ministry of Posts and Telecommunications which promotes the development of Japan's telecommunication industry has a home page on the World Wide Web in English, not Japanese (Pollack, 1995). Japan has problems in the software market partly because of the need to work in English, in contrast to India which now has a thriving English-language based software industry.

In other domains English also holds sway. Very many international conferences in all kinds of fields, no matter where in the world they are held, function with English at least as one of the official languages, if not the official language. International organisations likewise commonly use English as the sole official language or at any rate as one of those languages. The language of popular music and youth culture often is American or British English. The English language for many years has functioned as an auxiliary language in air traffic control. In many parts of the world it is the "lingua franca" for communication between hotel staff and guests, and so on: the number of examples that could be cited are numerous.

Not only is English widely used as an international language, but its effect on other languages is often noted. French intellectuals frequently complain about the introduction of English words to the French language like weekend, ferry-boat, bowling, escalator (golf) green, light (beer) and freelance instead of the French words fin de semaine. traversier, salle de quilles, escalier mobile, vert, legere and pigiste. According to somelinguists, English is also influencing the Korean language, again by importing English words: English is considered prestigious and English- like structures are therefore increasingly applied in Korean publications (Jinyoung, 1994; Baik, 
1994)

English, certainly, is no more neutral politically or culturally than any other language: native-speakers reap many advantages from the fact that their language is so widely used internationally. For some countries it also is a reminder of a colonial past. In its role as an international language, the political, historical and political bias of English undoubtedly is a shortcoming. Furthermore, as a natural language English has its share of irregularities. Wells (1988) opposes English as an international language because of its nonnormalised pronunciation, word-formation shortcomings, ambiguous morphology and complex syntax. In particular, learners can find it difficult to write "good" English as judged by the standards of native users. On the other hand, the emergence of variant forms in the language - American English, Australian English, Indian English, and so on - has helped to create a certain level of tolerance for non-standard usages as judged by any particular group of English- speakers.

\section{The Future of English}

The role of English as a medium of international communication has developed apace during the last thirty years. Will this development continue? It may well be that English by now has passed that critical point beyond which its future as an international language is assured. Teachers of English as a foreign language are in demand the world over and ever more people have some grasp of the language. The political and economic dominance of the premier English-speaking country, the United States, has never been greater. Despite the fact that the European Union only uses English as one of its official languages, throughout Europe English is a common interlanguage; a Dane or German, for example, may well use it as the interlanguage to communicate with a Spaniard or Greek. Decsy (1993) reports that Eurish (Euro-English) is the unrivaled Common European Second Language and that it has avoided pidginisation 
and creolisation due to excellent language teaching. This is not, of course, to argue against the continued importance of other languages, nor to argue that English can always be used today as an international language in daily business dealings (see Reeves, 1990 and Fixman. 1990)

As the global economy continues its growth, the need for an international medium of communication will become more pressing. If the role of English as an inter4anguage is eroded, it must be replaced by some other language. What might that be? Languages in the past have been spread by migration - of entire peoples or their commercial, religious and military representatives. A major change in the political/economic balance of power in the world might affect English. Such an effect, however, might be long in coming. Latin continued to act as a language for international communication within Europe for many hundreds of years after the collapse of the Roman Empire. It is hard to see in the foreseeable future Chinese or Japanese, for example, assuming the global role currently occupied by English. Might a constructed language such as Esperanto dislodge English from its position? This seems highly improbable. It would require the consent of states and individuals alike, including all those throughout the world who already have a command of English, the very people who tend to be most active internationally. The most pressing argument to support such a usurpation would be the unfair advantage given to native speakers of English in the world arena. It may well be, however, that English in future will not be seen as the language of a chosen few countries but as the property of everyone who chooses to learn it (see Peter, 1994). As Beneke (1980) argues, English as a communication medium need not conform to strict Anglo-US "correctness". The burst of activity by language thinkers and planners in seventeenthcentury Europe coincided with the decline of Latin as the language of scholarly communication. Unless the fortunes of English are reversed, constructed languages seem set to remain the enthusiastic concern of a tiny minority. 


\section{References}

Baik, Martin Jonghak (1994). Syntactic features of Englishisation in Korean World Englishes 13 (2) 155-166

Beneke, Jurgon (1981). Cultural monsters, mimicry and English as an international language. Language Incorporated: Teaching Foreign Languages in Industry. London: Pergamon

Boulton, Marjorie (I960). Zamenhof, Creator of Esperanto. London: Routledge \& Kegan Paul

Crystal, David (1995). The Cambridge Encyclopedia of the English Language. New York: Cambridge University Press

Cumming. John D. (1995). The Internet and the English language. English Today 11(1) 3-8

De Swaan. Abram (1991). Notes on the emerging global language system: regional, national and supranational. Media, Culture and Society 13, 309-323

Decsy, Gyula (1993). Europe's linguistic future: the Eurish problem, Eurasian Studies Yearbook 63,7-18

Dulicenko, Aleksandr Dmitrievic (1989). Ethnic language and planned language.

Fixman, Carol S. (1990). The foreign language needs of US-based corporations. Annals of the American Academy of Political and Social Science 511,2546

Garfield. Eugene \& Welljams-Dorof, Alfred (1990). Language use in international research: a citation analysis. Annals of the American Academy of Political and Social Science 511, 10-24

Glossop, Ronald J. (1988). Language policy. In Klaus Schubert. Interlinguistics: Aspects of the Science of Planned Languages. Berlin: Mouton, p. 47-61y and a just world order. Alternatives 13 (3) $395 " 409$

Guerard, A.L. (1945). Europe Free and United. Stanford: Stanford University Press

Jinyoung, Rosa (1994). Englishised Korean: structure, status and attitudes. World Englishes 13 (2) 225-244

Large, Andrew (1985). The Artificial Language Movement. Oxford: 
Blackwell

Maxwell, Dan (1988). On the acquisition of Esperanto. SSLA 10, 51-61

Pei, Mario (1958). One Language for the World. New York: DevinAdair

Peter, Steve (1994). Norma and meaning potential. World Englishes 13 (3) 387-394

Piron. Claude (1989). A few notes on the evolution of Esperanto. In Klaus Schubert. Interlinguistics: Aspects of the Science of Planned Languages. Berlin: Mouton, p. 129-142

Pollack, Andrew (1995). English becomes sensitive topic in the global village's Net The Gazette 13 August, B1, B6

Reeves, Nigel B.R. (1990). The foreign language needs of UK-bases corporations. Annals of the American Academy of Political and Social Science 511, 60-73

Sonnenfeld, Ernesto (1988). Cu Esperanto estas europa lingvo? La Revuo Oreinta 69 (4) 4-8

Wilkins. John (1668).An Essay Towards a Real Character and a Philosophical Language. London: Sa. Gellibrand \& John Martin 